\title{
Monitoring Of Antimicrobial Effect of GC-MS Standardized Melaleuca alternifolia Oil (Tea Tree Oil) On Multidrug Resistant Uropathogens
}

\author{
${ }^{1}$ Archana Kulkarni, ${ }^{2}$ Nasreen Jan and ${ }^{* 3}$ Seema Nimbarte \\ '(Department of Microbiology, Dharampeth M.P.DEO Memorial Science College, Nagpur, India.) \\ ${ }_{2}^{2}$ (PGTD of Microbiology, LIT Premises RTM Nagpur, Nagpur, India.) \\ ${ }^{3}$ (Department of Microbiology, Sevadal Mahila Mahavidyalaya Nagpur, Maharashtra State, India.)
}

\begin{abstract}
The aim of this work was to investigate antimicrobial action of tea tree oil (TTO) against multidrug resistant uropathogens. TTO was analysed by GC-MS studies. 16 compounds representing approximately $99 \%$ of the oil were characterized. The major compounds were Limonene, $\gamma$-Terpinene, $\alpha$-Terpinene, Cineol and $\alpha-$ Terpinolene. Further the antimicrobial effect of whole TTO was tested against the isolated uropathogens like Escherichia coli, Pseudomonas aeruginosa, Klebsiella pneumoniae, Proteus vulgaris, P. mirabilis and Staphylococcus aureus. The antibacterial action of TTO was determined by disc diffusion method and MIC was determined by broth microdilution method. The ZOI (mm) and MIC (\%) was in the range of $16 \pm 4 \mathrm{~mm}$ and $0.075 \%$ ( $v / v$ equivalent) for E. Coli; $20 \pm 2 \mathrm{~mm}$ and $0.03 \%$ for S. aureus; $19 \pm 2 \mathrm{~mm}$ and $0.10 \%$ for $\mathrm{K}$. pneumoniae; $19 \pm 2 \mathrm{~mm}$ and $0.03 \%$ for Proteus mirabilis; $20 \pm 2 \mathrm{~mm}$ and $0.038 \%$ for Proteus vulgaris. TTO showed low MIC values and high growth inhibition zone diameter in comparison to broad spectrum antibiotics - erythromycin, ampicillin, kanamycin, streptomycin and gentamycin. The result of the bioassay showed that oil possesses potent antibacterial and bacteriostatic property. This paper reviews the classical methods commonly used for evaluation of antibacterial activity of TTO and gives an overview on the susceptibility of human pathogens towards TTO and their constituents.
\end{abstract}

Key words: $\alpha$-terpineol, $\alpha$-terpinen-4-ol, linalool, multidrug resistance, tea tree oil, uropathogens.

\section{Introduction}

Among the array of microbial diseases, urinary tract infection (UTI) is a serious health problem that affects millions of people worldwide each year. UTI is a common ailment that exceeds in frequency among ambulatory patients only by respiratory and gastrointestinal infection. W.H.O has described UTI as one of the major infectious disease having huge economic impact. Women are more prone to UTI than men. Panda et al. (1966) observed that incidence of infection has been greater in females, between the age group of 21-40 years. In males, the highest incidence was found in the age group of 31-40 years. At the latter end of life, UTI becomes increasingly common, reaching to about $30 \%$ of the population. The rising prevalence is attributed to prolapsed and prostatism.

The main causative agents of UTI are of bacterial and fungal origin. Most UTI's in children are monomicrobic caused by Escherichia coli, Pseudomonas aeruginosa, Klebsiella pneumoniae, Proteus vulgaris, P. mirabilis and coagulase negative Staphylococcus aureus. UTI may also be caused by Group B Streptococci species and fungi Candida albicans. Chlamydia and Mycoplasma species are known to cause UTI in both men and women. The nosocomial route for acquiring UTI is reported as one of the most important routes.

The discovery, development and clinical use of antibiotics and a number of structurally diverse, highly effective antimicrobial agents helped in combating the UTI infections. However, paralleled to this, there has been an alarming increase in bacterial resistance to existing agents. The problem of antimicrobial resistance is mainly due to the reason that R-plasmid carrying strains have suddenly appeared and with their arrival, high level of resistance to several antibiotics have been encountered. Drug resistant plasmids are widely distributed in clinical bacterial isolates and consequent inheritance of multiple antibiotic resistances by these strains can severely impede the quick and easy treatment of bacterial infection. The prevalence of antimicrobial resistance in both, outdoor and hospital patients with UTI is increasing and can vary according to geographical and regional location (Mathai et al., 2001; Karlowsky et al., 2001).

In view of this, the need to find novel, reliable and effective antiuropathogenic agents is necessary and the less explored area of phytochemicals is a promising field. Therefore there is a scope for using methods of treatment which has a natural or green image. One such possibility is the use of essential oil of Melaleuca alternifolia (tea tree oil). Melaleuca alternifolia oil (Tea tree oil) is a natural product with strong antibacterial, antifungal, and anti-inflammatory activity. Tea tree oil (TTO) has many medicinal values and even fights 
organisms that are resistant to antibiotics. TTO happens to be an excellent home remedy for bacterial and fungal skin ailments, and also in relieving muscle and joint pain.

Tea tree oil has shown early promise as effective against controlling the growth of a wide variety of bacteria, including some drug resistant strains. The present study was undertaken to understand the extent of the efficacy of the EO.

The pharmacological screening of TTO was carried out against the pathogens isolated from UTI patients. The phytochemical analysis of TTO was carried out using Gas Chromatography- Mass Spectroscopy (GC-MS) technique. GC-MS studies revealed the presence of $\alpha$-terpinen-4-ol, linalool and $\alpha$-terpineol that are responsible for its antimicrobial and antifungal activity.

\subsection{Collection of Uropathogens}

\section{Materials And Methods}

In the present study, 182 urinary isolates were collected from various Pathology laboratories of Nagpur, India. The cultures were maintained on Trypticase Soya Agar (M990) and stored at $4{ }^{\circ} \mathrm{C}$.

\subsection{Reference Cultures}

The reference cultures of Escherichia coli ATCC 25922 (beta-lactamase negative), Pseudomonas aeruginosa MTCC 741, Klebsiella pneumonia MTCC 432, Proteus vulgaris MTCC 426, P. mirabilis MTCC 425 and Staphylococcus aureus MTCC 96 were collected from Institute of Microbial Technology, Chandigarh (MTCC ), India.

\subsection{Collection of Antimicrobial Agents}

The essential oil of Melaleuca alternifolia was procured from Dr. Urjita Jain's Forest Herbals Pvt. Ltd. Mumbai. Antibiotics with varying concentrations were supplied by Hi-media Laboratories, Mumbai.

\subsection{Antibiotic Susceptibility Testing}

Antibiogram of the urinary isolates was done by Kirby - Bauer's method using antibiotic discs of Ampicillin (10mcg), Kanamycin (30mcg), Streptomycin (10mcg), Tobramycin $(50 \mathrm{mcg})$, Norfloxcacin (10mcg), Co-trimoxazole $(25 \mathrm{mcg})$, Chloramphenicol $(30 \mathrm{mcg})$, Colistinmethane sulphonate $(100 \mathrm{mcg})$, Gentamycin $(10 \mathrm{mcg})$, Nalidixic acid $(30 \mathrm{mcg})$, Trimethoprim $(5 \mathrm{mcg})$, Tetracycline $(100 \mathrm{mcg})$, Amoxycillin $(30 \mathrm{mcg})$, Cephatoxime $(30 \mathrm{mcg})$. The results were interpreted as per Clinical and Laboratory Standards Institute CLSI, 2005 recommendations.

\subsection{Antimicrobial Activity of Essential Oils}

A commercial preparation of M. alternifolia of unknown concentration but potentially as high as $100 \%$ was obtained from Urjita Jain's Herbal Laboratory and subjected for antiuropathogenic activity using the paper disc diffusion method (Kirby and Bauer, 1966). For this, sterilized blank Whatman filter paper discs of size $6 \mathrm{~mm}$ were used. These discs were impregnated with essential oil (TTO) for 20 minutes and kept in slanted position so as to drain off excess oil. These discs were later weighed and amount of oil per disc was fixed at $15 \mathrm{mg}$. A lawn culture of test strain on Mueller-Hinton agar was exposed to the discs of oil. The discs were placed in the centre of the plate. All the plates were kept in refrigerator for a period of 30 minutes to facilitate diffusion and then incubated at $37^{\circ} \mathrm{C}$ for $24 \mathrm{hrs}$. After incubation, results were noted by measuring zone of growth inhibition in $\mathrm{mm}$ using zone reader and average values of three replicates were calculated for each isolate and recorded. The oil was also assayed for MIC determination using broth microdilution method.

\subsection{Gas Chromatography and Mass Spectroscopy (GC-MS) Studies}

The GC-MS studies were performed using Shimadzu QP-2000 GC/MS instrument at 70eV (unless otherwise specified) equivalent to OV-1, fused silica capacity - $0.25 \mathrm{~mm} \mathrm{X} 50 \mathrm{M}$ with film thickness - 0.25 micron. The entry on the GC- MS trace such as 100-6-10-250 means that the initial temperature was $100^{\circ} \mathrm{C}$ for 6 min and then heated at the rate of $10^{\circ} \mathrm{C}$ per minute to $250^{\circ} \mathrm{C}$. Carrier gas (helium) flow: $2 \mathrm{ml}$ per minute. Identification of GC-MS spectra is based on the direct comparison of Kovates index and mass.

\subsection{Minimum Inhibitory Concentration (MIC) of Tea Tree Oil}

The MIC of TTO against uropathogens was determined by using micro broth dilution method (Mann and Markham, 1998).

\subsubsection{Materials}

96 well $(88 \mathrm{mmx} 125 \mathrm{~mm}$ ) (U shaped bottom) micro titre plate (laxbro), Tween 20 or Tween 80 emulsifier, Nutrient broth (NB) and Mueller- Hinton broth (MHB). 


\subsubsection{Preparation of Inoculums}

One or two morphologically similar colonies were selected and aliquot was transferred to a test tube containing nutrient broth and incubated at $37^{\circ} \mathrm{C}$ for $4 \mathrm{hrs}$. The density of the suspension was standardized by McFarland 0.5 standard.

\subsubsection{Procedure}

The microdilution was performed in 96 well microtitre plates with U- shaped bottom.

For testing non-water soluble Tea tree oil it was necessary to incorporate suitable emulsifier. Tween 80 and Tween 20 was used (Beyleir, 1979; Walsh and Longstaff, 1987; Patkar et al., 1993; Chand et al., 1995b). This emulsifier showed good miscibility with Tea tree oil. 5\% Tween 20 emulsifier base was prepared in MHB. In this $5 \%$ solution of $M$. alternifolia was prepared.

For microdilution, $200 \mu \mathrm{l}$ of stock solution of M. alternifolia (Tea tree oil) was first transferred to the first column of microtitre plate (Well A to $\mathrm{H}$ ).

$100 \mu 1$ of MHB was transferred into all the wells of column 2 to 10.

Afterwards, stock solution of Tea tree oil was subjected to two-fold serial dilution ranging from $5 \%$ to $0.00976563 \%$, from $2^{\text {nd }}$ to $10^{\text {th }}$ well. Column $11^{\text {th }}$ and $12^{\text {th }}$ were kept as negative and positive control respectively.

$5 \mu$ l of test culture comprising to a cell density of $0.5 \mathrm{McF}$ arland Scale was added to the wells from $1^{\text {st }}$ to $10^{\text {th }}$ well and into $12^{\text {th }}$ well.

Plates were sealed, placed in plastic bags and incubated at $37^{\circ} \mathrm{C}$ for $24 \mathrm{hrs}$. And MIC was recorded as the lowest percentage of essential oil that exhibited no growth by usual reading.

Same procedure was repeated for all the bacterial isolates.

MIC is expressed as the highest dilution which inhibited growth, judged by lack of turbidity in the well, observed visually with aid of a reading mirror.

\subsection{Consortium of Uropathogens}

\section{Results And Discussions}

Out of the 182 clinical isolates of Uropathogens the most prevalent Uropathogen found in the consortium was E. coli $39 \%$ followed by P. aeruginosa $19 \%, K$. pneumoniae $16 \%, P$. vulgaris $10 \%$, S. aureus 9\%, P. mirabilis 7\%. The results were congruent to those reported by others. Ronald (2003) observed that the $E$. coli is the predominant uropathogen followed by Staphylococcs, Klebsiella and Proteus species. Vignesh et al., (2008) reported that E. coli was the most common etiological agent of UTI followed by P. aeruginosa and Klebsiella. These observations were also supported by the study of Pitout et al., (2005) and Pankaj Baral et al., (2012). Acharya V. N. (1980) also reported that $30 \%$ of all recurrent urinary infections were due to E. coli. Mohammad Akram et al., (2007) also reported that the E. coli (61\%) and Klebsiella (22\%) were predominant bacteria in UTI community.

\subsection{Antibiotic Response of Uropathogens}

Escherichia coli

The antibiotic resistance patterns of the clinically isolated uropathogens are presented in Table- 3.2.1

Out of 70 clinical isolates more than $50 \%$ isolates showed resistance to different antibiotics. $85 \% \mathrm{E}$. coli were resistant to Ampicillin, 60\% to Streptomycin, $68.5 \%$ to Gentamycin, $72.8 \%$ to Kanamycin and $71.4 \%$ to Erythromycin. The lowest resistance of E. coli was recorded for antibiotics like Cefuroxime, Nitrofurantoin and Norfloxacin. The results were confirmed with the reference culture of E. coli (ATCC 25922).

These observations are well supported by the previous studies of Oteo et al., (2006) who reported that the E. coli strains show 68\% resistance to Ciprofloxacin, 70\% to Gentamycin, 55\% to tobramycin, $63 \%$ to Amoxicillin and 54\% to Trimethoprim-Sulphamethoxazole.

Samuel et al. (1968) reported 59.75\% resistance to Ampicillin, Mohammed Akram et al., (2007) reported $76 \%$ and Singh et al. (1979) reported 85.2\%.

Naber et al. (1987) and DeMoy et al. (1989) reported resistance of 10\% of E. coli to Ciprofloxacin and $13.3 \%$ to Trimethoprim- Sulphamethoxazole. Mazzulli (2002) also reported $14 \%$ to $31 \%$ resistance to Trimethprim- Sulphamethoxazole. these findings.

Vignesh et al. (2008) showed $83.3 \%$ resistance to Sulphamethoxazole. Our study also corrobrotes with 
Monitoring Of Antimicrobial Effect Of Gc-Ms Standardized Melaleuca Alternifolia Oil (Tea Tree Oil)

Table-3.2.1: Antibiotic resistance shown by different Uropathogens

\begin{tabular}{|c|c|c|c|c|c|c|c|}
\hline $\begin{array}{l}\text { Sr. } \\
\text { No. }\end{array}$ & Antibiotics & $\begin{array}{l}\text { \%of } \\
\text { Resistant } \\
\text { samples of } \\
E \text {. coli } \\
(\mathrm{N}=70)\end{array}$ & $\begin{array}{l}\text { \%of } \\
\text { Resistant } \\
\text { samples of } \\
P . \quad \text { mirabilis } \\
(\mathrm{N}=12)\end{array}$ & $\begin{array}{l}\text { \%of } \\
\text { Resistant } \\
\text { samples of } \\
P . \quad \text { vulgaris } \\
(\mathrm{N}=19)\end{array}$ & $\begin{array}{l}\text { \%of } \\
\text { Resistant } \\
\text { samples of } \\
\text { P. aeruginosa } \\
(\mathrm{N}=35)\end{array}$ & $\begin{array}{l}\text { \%of } \\
\text { Resistant } \\
\text { samples of } \\
\text { S.aureus } \\
(\mathrm{N}=16)\end{array}$ & $\begin{array}{l}\text { \%of } \\
\text { Resistant } \\
\text { samples of } \\
\text { K. pneumoniae } \\
(\mathrm{N}=30)\end{array}$ \\
\hline 1 & Ampicillin & 85.7 & 75.0 & 78.9 & 80 & 87.5 & 63.33 \\
\hline 2 & Streptomycin & 60.0 & 50.0 & 47.9 & 68.57 & 62.5 & 53.33 \\
\hline 3 & Chloramphenicol & 42.8 & 33.3 & 52.6 & 57.1 & 56.2 & 46.66 \\
\hline 4 & Tetracycline & 34.2 & 33.3 & 47.9 & 51.4 & 68.7 & 50 \\
\hline 5 & Tobramycin & 31.0 & 41.6 & 42.3 & 57.1 & 56.2 & 40 \\
\hline 6 & Gentamycin & 68.5 & 33.3 & 47.9 & 51.4 & 62.5 & 46.66 \\
\hline 7 & Kanamycin & 72.8 & 41.6 & 42.3 & 48.5 & 68.7 & 36.66 \\
\hline 8 & Nitrofurantoin & 28.0 & 33.3 & 36.8 & 42.8 & 25.0 & 30 \\
\hline 9 & Norfloxacin & 28.0 & 25.0 & 26.0 & 28.5 & 31.2 & 23.33 \\
\hline 10 & Co-trimethprim & 47.1 & 58.3 & 36.8 & 28.5 & 62.5 & 53.33 \\
\hline 11 & Nalidixic acid & 31.0 & 41.6 & 42.3 & 40.0 & 50.0 & 36.6 \\
\hline 12 & Erythromycin & 71.4 & $\mathrm{Nt}$ & $\mathrm{Nt}$ & $\mathrm{Nt}$ & 75.0 & $\mathrm{Nt}$ \\
\hline 13 & Colistin & 42.8 & $\mathrm{Nt}$ & $\mathrm{Nt}$ & 68.5 & 56.2 & $\mathrm{Nt}$ \\
\hline 14 & Sulphamethoxazole & 45.7 & $\mathrm{Nt}$ & $\mathrm{Nt}$ & 57.1 & 50.0 & $\mathrm{Nt}$ \\
\hline 15 & Cefuroxime & 28.0 & $\mathrm{Nt}$ & $\mathrm{Nt}$ & $\mathrm{Nt}$ & $\mathrm{Nt}$ & $\mathrm{Nt}$ \\
\hline 16 & Cephatoxime & $\mathrm{Nt}$ & 25.0 & 26.0 & 28.5 & 62.0 & 40 \\
\hline
\end{tabular}

N- No. of samples, NT - Not tested

\section{Proteus mirabilis and Proteus vulgaris}

Out of 12 strains of Proteus mirabilis, high resistance was recorded against Ampicillin 75\% followed by Streptomycin $50 \%$, Tobramycin $41 \%$, Kanamycin $41 \%$, Co-trimethoprim $58.8 \%$, Nalidixic acid $41.6 \%$ and Cephatoxime $25 \%$.

Out of 19 strains of Proteus vulgaris, a maximum of $78 \%$ isolates were found to be resistant to Ampicillin, 52.6\% against Chloramphenicol, 47.9\% against Streptomycin and 47\% against Tetracycline. Resistance of these uropathegnic cultures were compared with reference culture Proteus mirabilis (MTCC 425) Proteus vulgaris (MTCC 425).

The studies reported by many scientists mention that Proteus species was the third commonest type of organism from patient with UTI. Furthermore, Proteus mirabilis is the commonest type (8.1\%), followed by $P$. vulgaris (5.4\%) (Rhoads et al. 1952 (4.3\% resistant isolates); Keeper, 1957,(5.6\% resistant isolates); Bhaskaran and Rao,1963,(7.5\% resistance isolates); Garrod et al., 1954 (45.8\% resistance isolates); Chakraborty et al., 1972, (43.0\% resistant isolates) and Singh et al., 1979 in his study found that Proteus species were resistance to Ampicillin $85.8 \%$, Chloramphenicol $21 \%$ and Nitrofurantoin $57.4 \%$. Our findings also corroborates with this study.

It is clear from the existing literature as well as the present study that the resistance of Proteus species to variety of antibiotics is increasing all the time. Thus, these results do highlight the necessity for further investigations and a continuous monitoring of the efficiency of various antibiotics for management of the UTI.

\section{Klebsiella pneumoniae}

The $K$. pneumoniae isolates also showed widespread multidrug resistance against the selected antibiotics. Out of 30 clinical isolates more than 50\% isolates were resistant to Ampicillin (63.3), Streptomycin (53.3), Co-trimethoprim (53.3\%), Tetracyclin (50\%). The antibiotic pattern was also compared with reference culture K.pneumoniae (MTCC 432).

Similar results, however with slight differences in the percentage of multidrug resistance pattern of K.pneumoniae was reported by Panda et al. (1966).

Mohammad Akram et al. (2007) observed in his study that $75 \%$ of K.pneumoniae isolates were resistance to Ampicillin which almost coincides with our findings. Furthermore, Naber et al. (1987), and Akram et al. (2007) support the observation that Klebsiella species constitute the second most common organism isolated from UTI.

\section{Pseudomonas aeruginosa}

Out of 35 clinical isolates of $P$. aeruginosa, $80 \%$ were highly resistant to Ampicillin, followed by Chloramphenicol $57.1 \%$, Tetracyclin $57.1 \%$ Gentamycin 51\%, Kanamycin 48\%, Sulphamethxazole $57.1 \%$ and Colistin $68.5 \%$

Chamber and Sande (1995) observed that $P$. aeruginosa was highly resistant to Kanamycin. Schassan in 1996 reported that $46.4 \%$ strains of $P$. aeruginosa were resistant to Kanamycin. Our results show $48.5 \%$ resistance to $P$. aeruginosa. Our results were congruent to these findings. 


\section{Staphylococcus aureus}

Highest percentage $(87.5 \%)$ of the isolates of $S$. aureus showed resistance to Ampicillin. $>50 \% S$. aureus strains showed resistance against majority of the selected antibiotics with exceptions being Nitrofurantoin and Norfloxacin. The above values are similar to reference culture of S. aureus (MTCC96). The resistance pattern of Staphylococcus aureus has been reported elsewhere by Jihad Bishara et al., 1997. He reported that hospital -acquired MRSA were resistant to chloramphenicol (69\% in 1988 and 100\% in 1997), gentamicin (89\% in 1988 to $94 \%$ in 1997), and ciprofloxacin (87\% in 1988 to $96 \%$ in 1997) and Fayaiz Ahmed et al., 2002 observed 62\% to Streptomycin and in 1992 Inouye observed 92\% resistance to Penicillin and 70\% to Kanmycin. All these observations warrant the detailed as well as continuous investigation and monitoring of $S$. aureus strains that are probable causative agent of UTI.

\subsection{Gas Chromatography - Mass Spectrometry}

Gas Chromatography - Mass Spectrometry (GC-MS) study was done to identify (qualitative estimation) different types of compounds present in TTO. The list of compounds identified with their corresponding retention time is presented in Table-3.3.1. The Mass Spectra of Melaleuca alternifolia is showed in Fig's 3.3.1 to 3.3.5.

Table-3.3.1: Identification of molecular mass of different compounds present in Melaleuca alternifolia oil using GC-MS analysis

\begin{tabular}{|l|l|l|l|l|l|}
\hline Peak\# & $\begin{array}{l}\text { Scan } \\
\text { No. }\end{array}$ & Compound & $\begin{array}{l}\text { Retention } \\
\text { Time (Min) }\end{array}$ & \% Area & Identification \\
\hline 1 & 430 & Limonene & 14.3 & 0.5 & ISO 4730 (2004) \\
\hline 2 & 781 & $\gamma$-Terpinene & 20.01 & 10.4 & ISO 4730 (2004) \\
\hline 3 & 826 & Citral-A & 27.5 & 2.4 & KI \\
\hline 4 & 865 & $\alpha$ - Terpinene & 28.8 & 12.7 & MS \\
\hline 5 & 894 & Gamma Terpinene & 29.76 & 2.9 & MS \\
\hline 6 & 1033 & 4- terpineol & 34.4 & 48.7 & MS \\
\hline 7 & 1051 & Cis- Sabinene hydrate & 35.01 & 2.3 & KI \\
\hline 8 & 1195 & P- cyeme-8-ol & 39.8 & 0.4 & MS \\
\hline 9 & 1276 & Aromadendrene & 42.5 & 1.7 & KI \\
\hline 10 & 1341 & P- cymene & 44.66 & 4.1 & MS,KI \\
\hline 11 & 1376 & $\alpha$ - pinene & 45.83 & 2.5 & MS,KI \\
\hline 12 & 1409 & Sabinene & 46.93 & 0.9 & MS,KI \\
\hline 13 & 1448 & $\alpha$ - Terpineol & 48.23 & 2 & MS \\
\hline 14 & 1464 & Bromy acetate & 48.76 & 0.4 & KI \\
\hline 15 & 1608 & Cineol & 53.56 & 7.3 & KI \\
\hline 16 & 1669 & $\alpha$ - Terpinolene & 55.6 & 1 & MS \\
\hline
\end{tabular}

KI = Kovates index; MS = Comparison of Mass Spectra

The Compounds Limonene, $\gamma$-Terpinene, $\alpha$-Terpinene, Cineol, $\alpha$-Terpinolene, are responsible for antimicrobial and antifungal activities. Identification is based on the direct comparison of Kovates index and mass Spectra.

Melaleuca alternifolia has the ability to kill a wide range of medically important micro-organisms, which was experimentally proved and confirmed with results of Shapiro et al., 1994; Carson et al, 1995; Hammer et al., 1996.

$\alpha$-terpinen-4-ol, linalool and $\alpha$-terpineol are lipophilic monterpenes and the major active antimicrobial components of Melaleuca alternifolia (Carson and Riley, 1995, 1994; Kim et al, 1995; Raman et al., 1995). Carson and Riley (1995) identified the components of $M$. alternifolia active against bacteria and yeast. Furthermore, Walsh et al., (1987) and Hammer et al.,(1996) studied the antimicrobial properties of $M$. alternifolia and reported the data of susceptibility of a wide range of bacteria. 


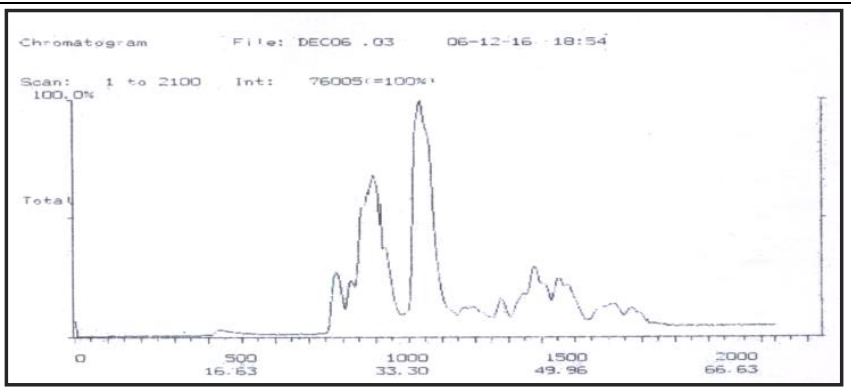

Fig: 3.3.1: GC-MS Chromatogram of M. Alternifolia

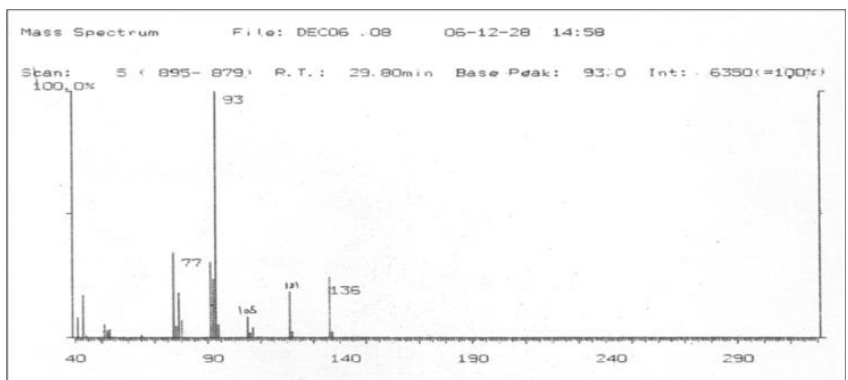

Fig: 3.3.2: Mass Spectrum of Gamma Terpinene

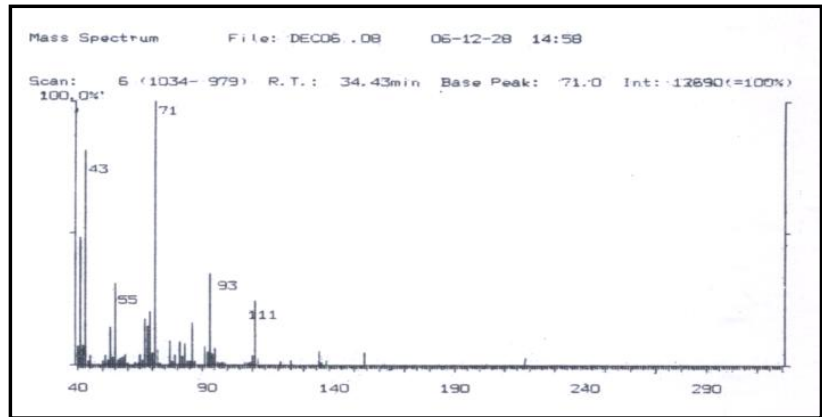

Fig: 3.3.3: Mass Spectrum of 4-terpineol

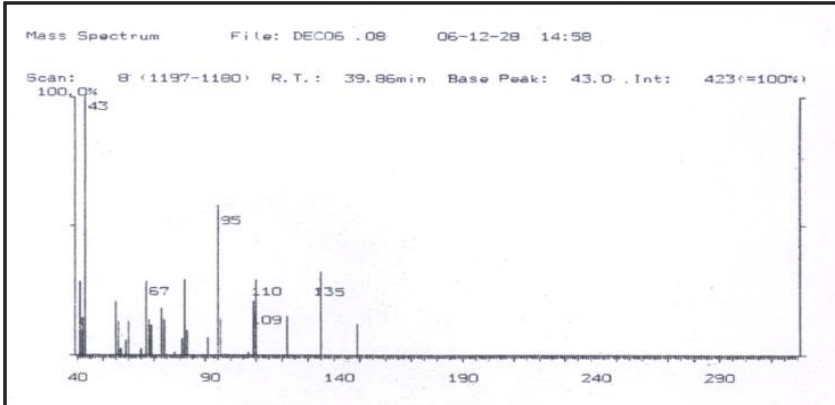

Fig: 3.3.4: Mass Spectrum of P-cyeme-8-ol

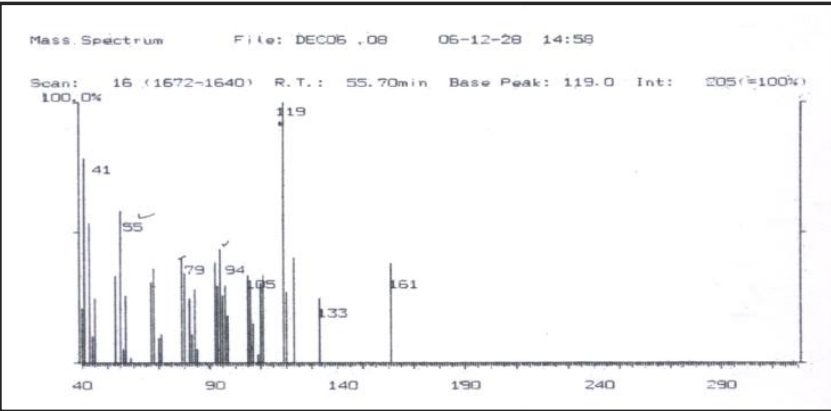

Fig: 3.3.5: Mass Spectrum of $\alpha$-Terpinolene 


\subsection{Susceptibility of Melaleuca alternifolia against Uropathogens}

The antimicrobial activity of Tea Tree oil against isolated uropathogens was determined by measuring the zone of inhibition (ZOI) of uropathogens. The results revealed that maximum ZOI of $20 \pm 2 \mathrm{~mm}$ was recorded with the oil of M.alternifolia. Table 3.4.1 shows that the oil of M.alternifolia was very promising for microbial control. These results are similar to those found by Carson and Riley (1994).

Table 3.4.1: Zone of inhibition recorded with Melaleuca alternifolia against different Uropathogens

\begin{tabular}{|l|l|l|l|l|l|l|}
\hline Sr. No. & Uropathogen & Mean & SD & Min & Max & Remark \\
\hline 1 & E. coli & 20 & \pm 2 & 17 & 24 & S \\
\hline 2 & S. aureus & 16 & \pm 2 & 10 & 22 & S \\
\hline 3 & P. aeruginosa & 6 & \pm 1 & 3 & 6 & R \\
\hline 4 & K. pneumoniae & 19 & \pm 2 & 17 & 22 & S \\
\hline 5 & P. mirabilis & 19 & \pm 2 & 15 & 22 & S \\
\hline 6 & P. vulgaris & 20 & \pm 2 & 18 & 23 & S \\
\hline
\end{tabular}

S: Susceptible; R: Resistant

The encouraging results indicate that the essential oil might be exploited as natural antimicrobial for the treatment of diseases caused by uropathogens could be useful in understanding the relations between traditional cures and current medicines.

\subsection{Minimum Inhibitory Concentration (MIC) of Melaleuca alternifolia}

The result of MIC determination using M.alternifolia oil indicted that minimum concentration of $0.03 \%$ (v/v equivalent) was effective against majority of micro-organisms (Cosentino et al., 1999; Faleiro et al., 2002), such as $P$. vulgaris $(0.03 \%)$ (v/v equivalent), P.mirabilis $(0.038 \%)$ (v/v equivalent) and E.colli $(0.031 \%)$ (v/v equivalent). However, the MIC for organisms, such as $S$. aureus, K. pneumonia are $0.25 \%$ (v/v equivalent) and $0.075 \%$ (v/v equivalent) for M.alternifolia oils which were similar to the findings of (Gustafson et al., 1998) $P$. aeruginosa showed resistance to all the concentrations of $M$. alternifolia in the present study which was also reported by (Carson et al., 1995). The MIC's of the essential oil reported here agree very closely with those found by other researchers working with E. coli strains in liquid media MICs of $0.03 \%$ and $0.08 \%(\mathrm{v} / \mathrm{v}$ equivalent) for oils derived from M. alternifolia (Farag et al., 1989; Hammer et al., 1999; Rota et al., 2004 and Smith-Palmer et al., 1998).

The MIC values for $K$. pneumoniae are $0.10 \%$ (v/v equivalent) and $0.04 \%$ (v/v equivalent) for our high sensitive oil of M. alternifolia. Similar results were observed by Jessica and Amy N. Morris (2008). Pseudomonas aeruginosa was the most resistant microorganisms to the essential oil tested among all the uropathogens. However, the MIC for Proteus vulgaris and Proteus mirabilis were obtained as $0.04 \% \mathrm{v} / \mathrm{v}$ and $0.038 \% \mathrm{v} / \mathrm{v}$ for trial of $M$. alternifolia.

The range of values in the literature reflects the differences in media composition, methodology and strains of bacteria used. The MIC results are represented in Table 3.5.1. The growth of P. aeruginosa was inhibited by terpinen-4-ol only but is very negligible in previous work using the same disc diffusion method whole oil failed to inhibit the growth of $P$. aeruginosa (Carson and Riley, 1994).

Table 3.5.1: MIC - Determination of Minimum Inhibitory Concentration (MIC) of Tea Tree oil against Uropathogens

\begin{tabular}{|l|l|}
\hline Uropathogens & $\begin{array}{l}\text { MIC of M.alternifolia oil } \\
\mathbf{( 0 . 0 5 \%} \text { v/v equivalent) }\end{array}$ \\
\hline Proteus vulgaris & $0.038 \%$ \\
\hline Proteus mirabilis & $0.038 \%$ \\
\hline Staphylococci aureus & $0.075 \%$ \\
\hline Escherichia coli & $0.031 \%$ \\
\hline Klebsiella pneumonia & $0.10 \%$ \\
\hline Pseudomonas aeruginosa & Resistant \\
\hline
\end{tabular}

The essential oil of Melaleuca alternifolia has had a long history of use as a topical antiseptic. Its activity against a range of bacteria and fungi has been the subject of many studies (Penfold and Grant, 1925; Walsh and Longstaff, 1987; Southwell et al., 1993; Carson et al., 1995; Hammer et al., 1996). Oil composition is variable but comprises about 50\% oxygenated monoterpenes and 50\% terpene hydrocarbon, with the principle active component being terpinen-4-ol (Southwell et al., 1993).

The MIC result obtained in this study provides valuable information regarding the use of essential oil to control the growth of various uropathogenic microorganisms including the important class of uropathogens. 
However, further optimization studies are warranted to delineate the guidelines for their direct therapeutic use addressing different disease conditions.

\section{Conclusion}

The findings of this study demonstrated an increase in the prevalence of resistance to a number of third generation antibiotics at an alarming level. This increased resistance of uropathogens is a matter of concern globally. Hence continuous monitoring of antibiotic susceptibility testing should be made mandatory to improve the empirical treatment.

In light of this a paradigm shift in the treatment of uropathogens is necessary to prevent antibiotics becoming obsolete, and where appropriate, alternative to antibiotic ought to be considered. The present study confirmed antimicrobial properties of essential oil of M. alternifolia. The oil shows promise as a broad spectrum antibacterial agent against Uropathogenic E. coli, which is the most common etiological agent and hence detailed study on this oil needs to be investigated as natural antibiotic.

\section{References}

[1] Acharya. V. N., Jadav. S. K., Urinary tract infection - Current status (Postgrad. Med.) 26(2), 1980, 95-98

[2] Akram. M., Shahid M., Khan A.U., Etiology and antibiotic resistance patterns of community- acquired urinary tract infections in JNMC Hospital Aligarh India, Ann. Clin. Microbiol. Antimicrob, 6:4,2007

[3] Baral. P., Neupane. S., Bishnu. P., Kashi. M., Ghimire. R, Lekhak. B., and Shrestha B., High prevalence of multidrug resistance in bacterial uropathogens from Kathmandu Nepal, BMC Research Notes, 5:38,2012

[4] Bauer. A. W., Kirby. M. M., Sharis. J. L, and Turck. M., Antibiotic susceptibility testing by a standard single disk method, Am. J. Clin. Pathol. 45, 1966, 493-496

[5] Beylier. M., Bacteriostatic activity of some Australian essential oils , Perfumer and Flavourist 4, 1979, 23-25

[6] Bhaskaran. C. S and Murti. B. R., J. IND. M.A., 1962, 38519

[7] Bishara. J., Pitlik. S., Samra. Z., Levy. I., Paul. M., Leibovici. L., Co-trimoxazole-sensitive methicillin-resistant Staphylococcus aureus Israel 1988-1997, Emerg. Infect. Dis, 2003, 9: 1168-1169

[8] Carson. C. F and Riley. T. V., Antimicrobial activity of the major components of the essential oil of Melaleuca alternifolia, Journal of Applied Bacteriology, 78, 1995, 264-269

[9] Carson. C. F., Hammer. K. A and Riley. T. V., Melaleuca alternifolia (Tea tree) oil: a review of antimicrobial and other medicinal properties ,Clin. Microbiol. Rev., 2006, 19:50-62

[10] Chakaraborty. P., Mehta. M. J., Roy. P. B., Shah. A. D, and Roy. S., J. of Indian Medical Association, 58, 1972, 113-116

[11] Chambers. H. F and Sande. M. A., Antimicrobial agents The Aminoglycosides In: Hardman I G Limbird CE Molinoff P B Ruddon R W and Goodman Gidman A (ed) The Pharmacological Basis of Therapeutics ,New York: McGraw Hill, 1995 pp $1103-1121$

[12] Chand S. I., Lusunzi D. A., Veal L. R., Williams and P. Caruso., Rapid screening of the antimicrobial activity of extracts and natural products ,J. Antibiot., 1994,47:1295-1304

[13] Cosentino. S., Tuberoso. C.I.G., Pisano. B., Satta. M., Mascia. V., Arzedi, E., Palmas. F., In-vitro antimicrobial activity and chemical composition of Sardinian Thymus essential oils , Letters in Applied Microbiology, 1999, 29: 130-135

[14] De Moy. D., Armengarud. M., Lefever. M. Discamps. G. Pagnom Maaurey. D. Auvio. J.C., Declerg. G., and Lapargneur. J.p., Pathol. Biol., 1989,37(5):402-5.

[15] Faleiro. M.L., M.G. Miguel. F. Ladeiro. F. Vanancio. R. Tavarses. J.C. Brito. A.C. Figueiredo. J.G. Barrosa and L.G. Pedro., Antimicrobial activity of essential oils isolated from Portuguese endemic species of Thymus, Lett. Appl. Microbiol., 2003, 36: 35-40

[16] Farag. R. S., Daw. Z. Y., Hewedi. F. M and EI-Baroty. G. S. A., Antimicrobial activity of some Egyptian spice essential oils, Journal of Food Protection, 1989, 52:665-667

[17] Fayaiz Ahmed, Baqir. S. Naqvi, Muhammad Harris Shoaib, Khurheed Hashmi* and Dilnawaz Shaikh., Resistance pattern of different aminoglycosides against gram positive and gram negative clinical isolates of Karachi, Pakistan Journal of Pharmaceutical Sciences vol.15, no.2, July 2002, pp.57-67

[18] Garrod. L. P., Shooter. R. A and Curwen. M. P., Brit. Med. J., 1954, 2:1003

[19] Gruneberg. R. N., Changes in urinary pathogens and their antibiotic sensitivities 1971-1992, J. Antimicrob. Chemother, 1994,33:1-8

[20] Gustafson. J. E., Liew. Y. C., Chew. S., Markham. J., Bell. H. C., Wyllie. S. G and Warmington. J. R., Effects of tea tree oil on Escherichia coli., Lett. Appl. Microbiol., 1998 26: 194-198

[21] Hammer. K. C., Carson and T. Riley., In-vitro activity of essential oils, in particular Melaleuca alternifolia (tea tree) oil and tea tree oil products against Candida spp , J. Antimicrob. Chemother. 1998, 42(5): 591-595 PMID 9848442

[22] Inouye. Y., Morifuji. K., Masumi. N., Nakamura. S., Takesue. Y., Santou. T. and Yokoyama, T., Susceptibility of methicillinresistant Staphylococcus aureus clinical isolates to various antimicrobial agents. II. Isolation of arbekacin-resistant strain, Hiroshima J. Med. Sci., 1992, 41(4): 79-85

[23] Jessica .A. Ott and Amy. N. Morris., Research Article: Homeopathic alterna to conventional antibiotics, BIOS, 2008 , 79(2): 50-55

[24] Karlowsky. J. A., Jones. M. E., Thornsberg. I. Critchley., Kelly. L. J and Sahm. D. F., Prevalence of antimicrobial resistance among urinary tract pathogens isolated from female outpatients across the US in1999, Int. J. Antimicrob. Agents, 2001, 18:121-127 [Pubmed]

[25] Keeper. C. S., Bull. Johns Hopkins Hosp., 1957, 100:107

[26] Kim. J., Marshall. M. R and Wei. C., Antibacterial activity of some essential oil components against five food borne pathogens, Journal of Agricultural and Food Chemistry, 1995, 43:2839-2845

[27] Mathai. D., Jones. R. N., Pfaller. M. A., The SENTRY Participant Group North America 2001 Epidemiology and frequency of resistance among pathogens causing urinary tract infections in 1,510 hospitalized patients: a report from the SENTRY Antimicrobial Surveillance Program (North America), Diagn. Microbiol. Infect. Dis., 2001, 40:129-136 [Pubmed]

[28] Mazzuli. T., Resistance trends in urinary tract pathogens and impact on management, J. Urol., 2002, 168 (4 Pt 2): 1720-2

[29] Naber. R. G and Glitternberger. R., Fortschr. Ants. Mikrob. Antineopiast. Chemoter. 1987, 6(8): 1279-90

[30] Oteo. J., Navarro. C., Cercenado. E., Delgado-Iribarren. A., Wilhelmi. I., Orden. B., Garcia. C., Miguelanez. S., Perez-Vazquez. M., Garcia-Cobos. S., Aracil. B., Bautista. V., Campos. J., Spread of Escherichia coli strains with high-level cefotaxime and Ceftazidime resistance between the community long-term care facilities and hospital institutions, 44(7): 2359-66

[31] Panda. G. K., Nanda. B. K and Rahim. M. A., J. Ind. M. A., 1966, 46:9 -13 
[32] Penfold. A. R and Grant. R., The germicidal values of some Australian essential oils and their pure constituents together with those for some essential oil isolates and synthetics Part III , J. R. Soc. New South Wales, 1925, 59: 346-349

[32] Pitout. J. D., Nordmann. P., Laupland. K. B., Poirel. L., Emergence of Enterobacteriaceae producing extended-spectrum betalactamases (ESBLs) in the community, J. Antimicrob. Chemother., 2005, 56: 52-59

[33] Raman. A., Weir. U and Loomfield. S. F., Antimicrobial effects of tea tree and its major components on Staphylococcus aureus S. epidermidis and Propionibacterium acnes., Lett. Appl. Microbiol., 1995, 21:242-245

[34] Rhoads. P. S., Billing. C. F and O'Conner. V. J., J. Amer. Med. Ass., 1952, 148:165

[35] Rota C Carraminana J J Burilo J and Herrara A 2004 In vitro antimicrobial activity of essential oils from aromatic plants against selected food borne pathogens (Journal of Food Protection) 67:1252-1256

[35] Samuel. K. C., Singh. R., Jain. S. C and Agarwal. S. V. M., J. Ind. M. A., 1968, 50(11)

[36] Shapiro. S., Meier. A and Guggenheling. B., Antiviral activity of essential oil components towards oral bacteria, Oral Microbiol. Immunol., 2001, 9:202-208

[37] Singh. S. N., Singh. S and Singh. K. N., J. Ind. Med. Assoc. 1979, 73:151-154

[38] Smith-Palmer. A., Stewart. J and Fyfe. L., Antimicrobial properties of plant essential oils and essences against five important food borne pathogens, Letters in food Microbiology, 1998, 26:118-122

[39] Southwell. I. A., Hayes. A. J., Markham. J and Leach. D. N., The search for optimally bioactive Australian tea tree oil, Acta Horticulture, 1993, 334: 256-265

[40] Southwell. I. A., Markham. J and Mann. C., "Is 1, 8-cineole detrimental to tea tree oil?", Perfum. and Flav., 1996, 21 (5) 7-10

[41] Vignesh. R., Shankar. E. M., Murugavel. K. G., Kumaraswami. N., Sekar. R., Irene. P., Solomon. S., Balakrishna. P., Urinary infections due to multi-drug-resistant Escherichia coli among persons with HIV disease at a tertiary AIDS care centre in South India, 2008, 110(1): c55-7 Epub 2008 Aug 25 Walsh L J and J Longstaff 1987 The antimicrobial effects of an essential oil on selected oral pathogens (Periodontology) 8: 11-15 